Check for updates

Cite this: RSC Adv., 2019, 9, 23727

Received 28th April 2019 Accepted 10th July 2019

DOI: 10.1039/c9ra03174j

rsc.li/rsc-advances

\section{Two-step catalytic conversion of lignocellulose to alkanes $\uparrow$}

\author{
Zhuohua Sun, ${ }^{*}$ Daniel Buwalda and Katalin Barta (D) *
}

Direct conversion of lignocellulose to alkanes is challenged by the complex and recalcitrant nature of the starting material. Generally, alkanes are obtained from one of the main lignocellulose constituents (cellulose, hemicellulose or lignin) after their separation, and platform chemicals derived therein. Here we describe a two-step methodology, which uses unprocessed lignocellulose directly, targeting a mixture of alkanes. The first step involves the near-complete conversion of lignocellulose to alcohols, using a copper doped porous metal oxide (Cu-PMO) catalyst in supercritical methanol. The second step comprises a novel solvent exchange procedure and the exhaustive hydrodeoxygenation (HDO) of the complex mixture of aliphatic alcohols, obtained upon depolymerization, to $\mathrm{C}_{2}-\mathrm{C}_{10}$ alkanes by either $\mathrm{HZSM}-5$ or Nafion at $180{ }^{\circ} \mathrm{C}$ in conjunction with $\mathrm{Pd} / \mathrm{C}$ in dodecane. This describes an unprecedented two-step process from lignocellulose to hydrocarbons, with an overall carbon yield of $50 \%$.

\section{Introduction}

With the decreasing oil reserves and concerns related to global warming due to $\mathrm{CO}_{2}$ emissions, it is vital to explore more sustainable sources of energy, including renewables, for producing liquid transportation fuels. ${ }^{1,2}$ The conversion of raw biomass to liquid transportation fuels would mean the acquisition of a fossil fuel replacement that is both $\mathrm{CO}_{2}$ neutral and renewable as it can be extracted from plant material. ${ }^{3,4}$ Lignocellulose, which is already produced in large quantities (about 368 million dry tons annually could be produced on forestlands in the US alone $)^{5}$ would be a starting material for the production of transportation fuels. ${ }^{6}$ Indeed, a variety of research directions have been established in the past few decades to attain this goal. ${ }^{7}$ Prominent research directions include thermal methods such as gasification (typically $\left.600-1200{ }^{\circ} \mathrm{C}\right)^{8}$ or pyrolysis (typically $\left.450-800^{\circ} \mathrm{C}\right)^{9}$ which require higher temperatures, or liquid phase approaches that generally involve the fractionation (pretreatment) of lignocellulose ${ }^{10}$ to its main constituents cellulose, hemicellulose or lignin and further conversion of these fractions. Important developments have been achieved in the production of second generation bioethanol, ${ }^{11,12}$ biobutanol $^{13}$ as well as alternative energy carriers such as GVL, ${ }^{14-16}$ levulinates ${ }^{17,18}$ or furanics ${ }^{19,20}$ obtained from cellulose or hemicellulose derived platform chemicals.

Producing liquid alkanes specifically has the advantage of delivering already known products, and such drop-in alkanes

Stratingh Institute for Chemistry, University of Groningen, Nijenborgh 4, 9747 AG Groningen, The Netherlands.E-mail: k.barta@rug.nl; sunzhuohua@yahoo.com $\dagger$ Electronic supplementary information (ESI) available: Characterizations of catalysts and the list of chemicals detected in the GC-MS. See DOI: 10.1039/c9ra03174j would be easily implemented into existing infrastructures. ${ }^{21}$ Indeed, several novel methods have been recently investigated regarding the conversion of lignocellulose to alkanes, most of which preferentially focused on the selective catalytic conversion of either lignin itself or cellulose derived platform chemicals. For example, organosolv lignin was converted to cycloalkanes in one-pot with high selectivity (>99\%) by supported Ni catalysts ${ }^{22,23}$ or Ru-based bifunctional catalysts ${ }^{24}$ via a cascade HDO reaction sequence. Liquid straight-chain alkanes were obtained directly from cellulose with high yield (up to $82 \%$ ) in a biphasic catalytic system using tungstosilicic acid and $\mathrm{Ru} / \mathrm{C}$ catalyst at $220{ }^{\circ} \mathrm{C} .{ }^{25}$ Such systems have been also integrated into existing refinery structures. ${ }^{26}$ Regarding the (hemi)cellulose platform, several elegant routes have been developed for the transformation of single compounds $\mathrm{HMF}^{27,28}$ furfural ${ }^{29,30}$ or the derived cyclopentanone ${ }^{31}$ into long chain alkanes that are suitable to use as jet fuels. ${ }^{32}$ These selective catalytic transformations generally comprise an acid or base catalysed aldol condensation or coupling, followed by deep HDO. Novel dehydrogenation/aldol condensation/ hydrogenation sequences have also been reported for the conversion of the ABE fermentation mixtures to long chain ketones followed by deep HDO. ${ }^{33,34}$ Very recently we have developed a method for the coupling of mixtures of aliphatic alcohols obtained from the 'Ligno-Flex' process using a $\mathrm{Cu}$ and $\mathrm{Ni}$ doped porous metal oxide catalyst. ${ }^{35-37}$

Approaches that use raw lignocellulose directly may circumvent the relatively energy-, time- and material-intensive lignocellulose pretreatment/fractionation process, albeit the difficulty of product separation moves downstream. Recently, several elegant examples of direct conversion of lignocellulose to alkanes have been reported. Wang and co-workers described 
the direct $\mathrm{HDO}$ of raw lignocellulose sources into liquid alkanes over a multifunctional $\mathrm{Pt} / \mathrm{NbOPO}_{4}$ catalyst. ${ }^{38} \mathrm{Ma}$ and co-workers reported the efficient conversion of lignocellulose into gasoline alkanes (hexanes and pentanes), monophenols and related cycloalkanes over layered $\mathrm{LiTaMoO}_{6}$ and $\mathrm{Ru} / \mathrm{C}$ in aqueous phosphoric acid medium. ${ }^{39}$

Copper doped porous metal oxides (Cu-PMOs) derived from synthetic hydrotalcites (HTC) have been established by Ford and co-workers as a highly interesting catalyst class for the conversion of renewable resources in supercritical methanol. ${ }^{40-43}$ Supercritical methanol, as well as the in situ generated hydrogen (from reforming a portion of the solvent) is beneficial for achieving hydrothermal conditions for the full conversion of lignocellulose solids into methanol soluble liquids under selected reaction conditions. ${ }^{\mathbf{4 0 , 4 3}}$ The main products of the liquid phase consist of a predominantly $\mathrm{C}_{2}-\mathrm{C}_{6}$ range aliphatic alcohols from cellulose and $\mathrm{C}_{9}$-range, cyclic aliphatic alcohols from lignin and their methylated derivatives as methanol solution. ${ }^{\mathbf{4 0 , 4 3}}$ Inspired by this precedence, we have attempted the detailed composition analysis of these mixtures, and investigate their conversion to more uniform mixtures of alkanes. First, we attempted to study the effect of different Cu-PMO catalyst compositions on the product distribution and the average chain lengths of the obtained alcohols. Second, we aimed to find ideal novel catalytic methods capable of deep HDO of such complex mixtures of predominantly aliphatic alcohols to liquid alkanes that would possess higher heating value than the corresponding oxygenates. ${ }^{44}$ Such a system has not yet been previously studied, very likely due to the methanol solvent, which may significantly complicate such downstream processing efforts. ${ }^{36}$ Herein we describe the successful, two-step conversion of lignocellulose to mixtures of alkanes. In addition, we have evaluated the reactivity of organosolv lignin extracted from pine lignocellulose as well as cellulose separately in order to compare the product portfolio to the lignocellulose conversion runs. For the corresponding HDO reactions, model compounds were used for investigating reactivity and optimization of the catalytic systems before moving to the more complex, real lignocellulose derived mixtures.

\section{Material and methods}

\section{General considerations}

Pine lignocellulose was purchased from Bemap Houtmeel B. V., elemental content C: 42.74\%; H: 6.19\%; O: 46.42\%. All reagents and solvents are used as received without further purification. $\mathrm{ZrO}_{2}, \mathrm{Nb}_{2} \mathrm{O}_{5}$, Nafion, $\mathrm{Pd} / \mathrm{C}(5 \%)$ catalysts was purchased from Sigma-Aldrich. Zeolite ZSM-5 (Si : Al 30 : 1) was purchased from Alfa Asea, before use it was calcined in the oven at $500{ }^{\circ} \mathrm{C}$ for 5 hours. USY-600 was purchased from Zeolyst International.

\section{Preparation and characterization of Cu-PMO catalysts}

The HTC (hydrotalcite) catalyst precursor was prepared by a typical co-precipitation method. ${ }^{45}$ In a typical procedure, a solution containing $\mathrm{AlCl}_{3} \cdot 6 \mathrm{H}_{2} \mathrm{O}(12.07 \mathrm{~g}, 0.05 \mathrm{~mol})$, $\mathrm{Cu}\left(\mathrm{NO}_{3}\right)_{2} \cdot 2.5 \mathrm{H}_{2} \mathrm{O}(6.98 \mathrm{~g}, 0.03 \mathrm{~mol})$ and $\mathrm{MgCl}_{2} \cdot 6 \mathrm{H}_{2} \mathrm{O}(24.40 \mathrm{~g}$,
$0.12 \mathrm{~mol})$ in deionized water $(0.2 \mathrm{~L})$ was added to a solution containing $\mathrm{Na}_{2} \mathrm{CO}_{3}(5.30 \mathrm{~g}, 0.05 \mathrm{~mol})$ in water $(0.3 \mathrm{~L})$ at $60{ }^{\circ} \mathrm{C}$ under vigorous stirring. The $\mathrm{pH}$ was kept between 9 and 10 by addition of small portions of a $1 \mathrm{M}$ solution of $\mathrm{NaOH}$. The mixture was vigorously stirred at $60{ }^{\circ} \mathrm{C}$ for $72 \mathrm{~h}$. After cooling to room temperature, the light blue solid was filtered and resuspended in a $2 \mathrm{M}$ solution of $\mathrm{Na}_{2} \mathrm{CO}_{3}(0.3 \mathrm{~L})$ and stirred for overnight at $40{ }^{\circ} \mathrm{C}$. The solids were filtered and washed with deionized water until chloride free. After drying the solid for $6 \mathrm{~h}$ at $100{ }^{\circ} \mathrm{C}, 15.07 \mathrm{~g}$ of the hydrotalcite (HTC) was obtained. $4 \mathrm{~g}$ of obtained hydrotalcite was then calcined at $460{ }^{\circ} \mathrm{C}$ for $24 \mathrm{~h}$ in air and yielded $2.5 \mathrm{~g}$ of Cu20-PMO catalyst.

The catalyst prepared in this procedure is a porous metal oxide (PMO), denoted as Cu20-PMO, which indicates that in a $3: 1 \mathrm{Mg} / \mathrm{Al}$ hydrotalcite precursor $20 \mathrm{~mol} \%$ of the $\mathrm{Mg}^{2+}$ ions were replaced with $\mathrm{Cu}^{2+}$ ions. Other catalysts with different $\mathrm{Cu}$ content were prepared in the same procedure but using different amounts of $\mathrm{Cu}\left(\mathrm{NO}_{3}\right)_{2} \cdot 2.5 \mathrm{H}_{2} \mathrm{O}$ and $\mathrm{MgCl}_{2} \cdot 6 \mathrm{H}_{2} \mathrm{O}$ salt and named as Cu5-PMO and Cu10-PMO respectively.

Powder X-ray analysis was performed on a Bruker XRD diffractometer using $\mathrm{Cu} \mathrm{K} \alpha$ radiation and the spectra were recorded in the $2 \theta$ angle range of $10^{\circ}-90^{\circ}$. Elemental analysis was performed on a PerkinElmer instrument (Optima 7000DV).

\section{Extraction of lignin from pine lignocellulose}

Extraction of lignin from pine lignocellulose was carried out in a $500 \mathrm{~mL}$ autoclave with an overhead stirrer and temperature controller. Typically the reactor was charged with $30 \mathrm{~g}$ of pine lignocellulose, $250 \mathrm{~mL}$ of methanol at room temperature. The reactor was sealed and stirred for $24 \mathrm{~h}$ at $170{ }^{\circ} \mathrm{C}$. During the reaction 25 bar of autogenous pressure was developed. After completion of the extraction, the reactor was cooled down to room temperature. The mixture was collected in a $1000 \mathrm{~mL}$ beaker by rinsing the reactor several times with methanol and then filtered. The solids were washed with methanol and the combined solution was concentrated to $100 \mathrm{~mL}$ by rotary evaporator and precipitated with ice-cold water and then stirred overnight. The mixture was then centrifuged and the solids (Lignin) were collected by decanting the solutions which contained hemicellulose. The obtained solid was finally dried under vacuum yielding $0.66 \mathrm{~g}$ organosolv lignin.

\section{Catalytic conversion of pine lignocellulose (Step 1)}

Pine sawdust (100 mg) and Cu-PMO catalysts (100 mg) were added to a $10 \mathrm{~mL}$ Swagelok stainless steel microreactor with $3 \mathrm{~mL}$ methanol as solvent. The reaction vessel was placed in a heating block at $320^{\circ} \mathrm{C}$ for $6 \mathrm{~h}$. The reactor was subsequently rapidly cooled down in an ice-water bath to terminate the reaction. The contents of the reaction vessel were transferred to a centrifuge tube and the solid was separated. The liquid layer was collected in a round bottom flask and the solid was washed twice with methanol. All liquid products were combined and methanol was removed by rotatory evaporation until approximately $5 \mathrm{~mL}$ liquid left. The products were then analyzed by GCMS. 
ATTENTION: Handle with care!! Upon heating to the indicated reaction temperature, autogenous pressure ( $>200$ bar) develops in these vessels due to the supercritical methanol and in situ formed hydrogen.

\section{HDO of model compounds}

Cyclohexanol (0.1 mL, $1 \mathrm{mmol}$ ) or alcohol mixture 1 (Mix1 containing 2-methylcyclohexanol, cyclohexanol, 4-methyl-2pentanol, 2-methyl-1-butanol, 2-ethylhexanol, 2-cyclohexylethanol, $0.17 \mathrm{mmol}$ for each and in total $0.128 \mathrm{~mL}$ ) or alcohol mixture 2 (Mix2 containing 1-pentanol, 1-hexanol, 1octanol, and 2-cyclohexylethanol, $0.25 \mathrm{mmol}$ for each and in total $0.136 \mathrm{~mL}$ ) were added to a reaction vessel with $50 \mathrm{mg}$ solid acid catalyst and $10 \mathrm{mg} \mathrm{Pd} / \mathrm{C}$ in $3 \mathrm{~mL}$ dodecane. The reaction vessel was placed in a high pressure stainless steel reactor (Endeavor@) and carefully purged with $\mathrm{N}_{2}$ for 3 times. Then the reactor was filled with $\mathrm{H}_{2}$ (10 bar) and heated to desired temperature. Next, the reaction mixture was transferred to a GC vial by filtration with a glass pipette equipped with a short pad of Celite and cotton pad. The products were analyzed by GC-MS and GC-FID.

\section{HDO of the product mixtures obtained by depolymerization of pine lignocellulose (Step 2)}

Solvent exchange. Dodecane $(5 \mathrm{~mL})$ was added to the methanol solution obtained directly after lignocellulose depolymerization in Step 1. Then methanol was carefully evaporated by rotary evaporator to leave a dodecane solution behind which contains most of the products from Step 1. Small amount of precipitate ( $\sim 10 \mathrm{mg}$ ) was also observed, which was not further treated.

HDO. The dodecane solution obtained above was then transferred to reaction vessel containing $50 \mathrm{mg}$ solid acid catalyst and $10 \mathrm{mg} \mathrm{Pd} / \mathrm{C}$. The reaction vessel was placed in a high pressure stainless steel reactor (Endeavor@) and purged with $\mathrm{N}_{2}$ for 3 times. Then the reactor was filled with $\mathrm{H}_{2}$ (10 bar) and heated to the desired temperature. The reaction mixture was next transferred to a GC vial by filtration over a PTFE filter and analyzed by GC-MS.

Upscaled HDO procedure. In order to more precisely calculate the final carbon yield and the yield of obtained alkanes, crude reaction mixtures from 10 separate small scale, $0.1 \mathrm{~g}$ pine lignocellulose depolymerization runs (see above Step 1) were combined. Then $(10 \mathrm{~mL})$ dodecane was added to this methanol solution and methanol was carefully evaporated by rotary evaporation resulting in a dodecane solution that contains most of the products from Step 1. The dodecane solution was then transferred to reaction vessel containing $0.5 \mathrm{~g}$ solid acid catalyst and $0.1 \mathrm{~g} \mathrm{Pd} / \mathrm{C}$ and subsequently, $10 \mathrm{mg}$ eicosane was added as internal standard. The reaction vessel was placed in a $100 \mathrm{~mL}$ Parr reactor that was subsequently pressurized with $10 \mathrm{bar} \mathrm{H}_{2}$. After reaction was conducted for 4 hours at $180{ }^{\circ} \mathrm{C}$, then the vessel was cooled to room temperature and depressurized. Next, the reaction mixture was transferred to a GC vial by filtration over a PTFE filter then analyzed by GC-MS and GC-FID. The gaseous products were collected into a gas bag and analyzed by GC-TCD.

\section{Analysis of liquid and gas products}

Products of the liquid phase, obtained in Step 1 (alcohol mixtures) and Step 2 (alkanes) are analyzed by GC-MS and GCFID. GC-MS was performed using a Shimadzu GC-2010 plus system equipped with a GCMS QP2010 GC SE detector and a HP5 column. The column was maintained at $30{ }^{\circ} \mathrm{C}$ for $5 \mathrm{~min}$, raised at $10{ }^{\circ} \mathrm{C} \min ^{-1}$ to $90{ }^{\circ} \mathrm{C}$, then raised at $25{ }^{\circ} \mathrm{C} \mathrm{min}{ }^{-1}$ to $250{ }^{\circ} \mathrm{C}$ and maintained for $10 \mathrm{~min}$. GC-FID was performed on a Hewlett Packard 6890 (HP-5 capillary column and a flame ionization detector (FID)). The column was maintained at $30{ }^{\circ} \mathrm{C}$ for $5 \mathrm{~min}$, raised at $10{ }^{\circ} \mathrm{C} \min ^{-1}$ to $90{ }^{\circ} \mathrm{C}$, then raised at $25{ }^{\circ} \mathrm{C} \min ^{-1}$ to $250{ }^{\circ} \mathrm{C}$ and maintained for $10 \mathrm{~min}$. A fraction of short chain alkanes obtained in Step 2 are normally gaseous at room temperature. These were analyzed by GC-TCD upon collection in a gas bag. A HP5890 Series II GC equipped with a CP Porabond Q $(50 \mathrm{~m} \times 0.5 \mathrm{~mm}$, film thickness $10 \mu \mathrm{m})$ and a CP-Molsieve $5 \mathrm{~A}(25 \mathrm{~m} \times 0.53 \mathrm{~mm}$, film thickness $50 \mu \mathrm{m})$ column was used for this purpose. The injector temperature was set at $150{ }^{\circ} \mathrm{C}$ and the detector temperature at $90{ }^{\circ} \mathrm{C}$. The oven temperature was kept at $40^{\circ} \mathrm{C}$ for $2 \mathrm{~min}$, then increased to 90 at $20{ }^{\circ} \mathrm{C} \min ^{-1}$, and kept at this temperature for $2 \mathrm{~min}$.

\section{Calculation of the overall yield of obtained alkanes}

The amount of obtained alkanes was calculated based on peak area in GC-FID with eicosane as internal standard.

Mass yield of obtained alkanes is calculated as follows:

$$
\operatorname{Yield}\left(\mathrm{wt}^{\mathrm{O}} \%\right)=\frac{W_{\text {alkanes }}}{W_{\text {lignocellulose }}}
$$

$W_{\text {alkanes }}$ means the weight of total obtained alkanes, $W_{\text {lignocellulose }}$ means the weight of total lignocellulose used in Step 1.

$$
\text { Yield }(C \%)=\frac{C_{\text {alkanes }}}{C_{\text {lignocellulose }}}
$$

means the carbon content of total obtained alkanes, $C_{\text {lignocellulose }}$ means the carbon content of total lignocellulose used in Step 1. The carbon content of the pine lignocellulose used in this study is $42.74 \%$.

\section{Results and discussion}

With the aim of converting raw lignocellulose to alkanes we have set to investigate a specific depolymerization/HDO sequence shown in Fig. 1, which consists of the

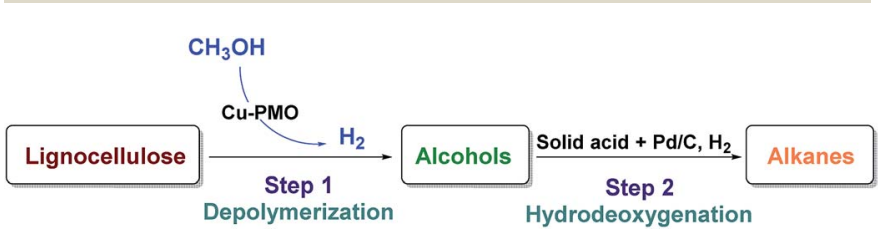

Fig. 1 Two-step catalytic conversion of lignocellulose to alkanes. 
depolymerization of raw lignocellulose to alcohols (Step 1) using a $\mathrm{Cu}-\mathrm{PMO}$ catalyst of varying composition in supercritical methanol and finding an appropriate method for the HDO of the produced alcohols to alkanes (Step 2).

\section{Depolymerization of lignocellulose with $\mathrm{Cu}-\mathrm{PMO}$ catalysts}

In order to investigate the influence of $\mathrm{Cu}$ content on reactivity, three different (HTC) precursors were prepared by coprecipitation, gradually replacing $5 \mathrm{~mol} \%, 10 \mathrm{~mol} \%$ and $20 \mathrm{~mol} \%$ of $\mathrm{Mg}^{2+}$ by $\mathrm{Cu}^{2+}$ while keeping a constant $3: 1$ ratio between divalent and trivalent metal ions. The porous metal oxide catalysts were next obtained upon calcination of the HTC precursors at $460{ }^{\circ} \mathrm{C}$ for 24 hours.

The composition of HTC (Table S1 $\dagger$ ) were in good agreement with the theoretically expected values, indicating good incorporation of the metal ions. The formation of the double-layered HTC structure was confirmed by powder XRD measurements (Fig. S1a $\dagger$ ). After calcination, the HTC structure was transformed into an amorphous mixed-oxide composition (Fig. S1b $\dagger$ ) where the broad peaks at $37^{\circ}, 43^{\circ}$ and at $63^{\circ}$ indicate the formation of spinels $\mathrm{MgAlO}_{2}$ and $\mathrm{CuAlO}_{2}$.

Depolymerization of pine lignocellulose in supercritical methanol (sc-MeOH) was carried out based on procedures described previously. ${ }^{43}$ After reaction, the transparent methanol solution of organic compounds was subjected to a detailed GCMS identification, whereby the major products were unambiguously identified by the use of authentic standards, and the remaining signals were assigned based on GC-MS library search with a similarity index above $70 \%$. A GC-MS trace of the sample after depolymerization of pine lignocellulose over Cu20-PMO, labeled with the chemical structures are shown in Fig. 2 . Detail product analysis by different catalysts were listed in Tables S2 and S3. $\dagger$ As shown here, most of products are alcohols or hydroxyl ethers with small amount of aromatics also detected. The formation of hydroxyl ethers is attributed to the further reaction of methanol with formed alcohols.
Upon careful analysis of the product mixtures obtained by using catalysts of varying $\mathrm{Cu}$ content, the results of products distributions as function of catalyst composition was summarized in Fig. 3 and Table $S 4, \dagger$ which clearly shows that the conversion of raw lignocellulose (from $89 \%$ to $97 \%$ ) and selectivity of alcohols (from $52.5 \%$ to $66.1 \%$ ) increased with the increase of copper content. This is very likely due to different extent of methanol reforming leading to different hydrogen pressure, and therefore different extent of lignocellulose deconstruction. At the same time, products with chain length of more than 7 decreased slightly with the increase of copper content - this is also attributed to hydrogenolysis processes being more pronounced with increasing hydrogen pressure in the case of Cu20-PMO as expected, while Cu5-PMO should resemble more to a classical hydrotalcite, preferably promoting aldol condensation steps that lead to chain elongation. ${ }^{33}$

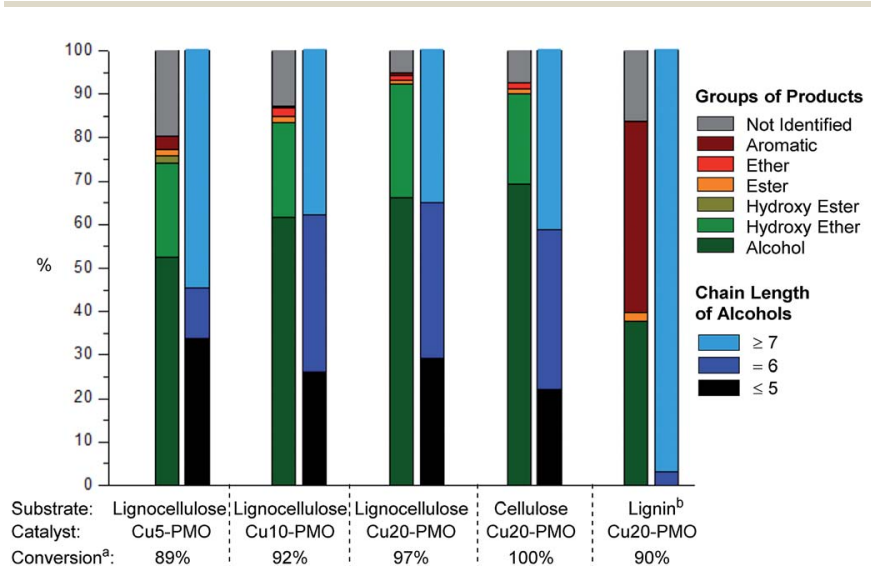

Fig. 3 Conversion, product distribution and average chain length of alcohols in various product mixtures obtained upon catalytic depolymerization of different substrates in $\mathrm{sc}-\mathrm{MeOH}$ over various PMO catalysts. Reaction conditions: substrate $100 \mathrm{mg}$, catalyst $100 \mathrm{mg}$, methanol $3 \mathrm{~mL}, 320{ }^{\circ} \mathrm{C}, 6 \mathrm{~h}$. (a) Conversion is determined by gravimetric analysis. (b) Lignin was obtained from pine lignocellulose.

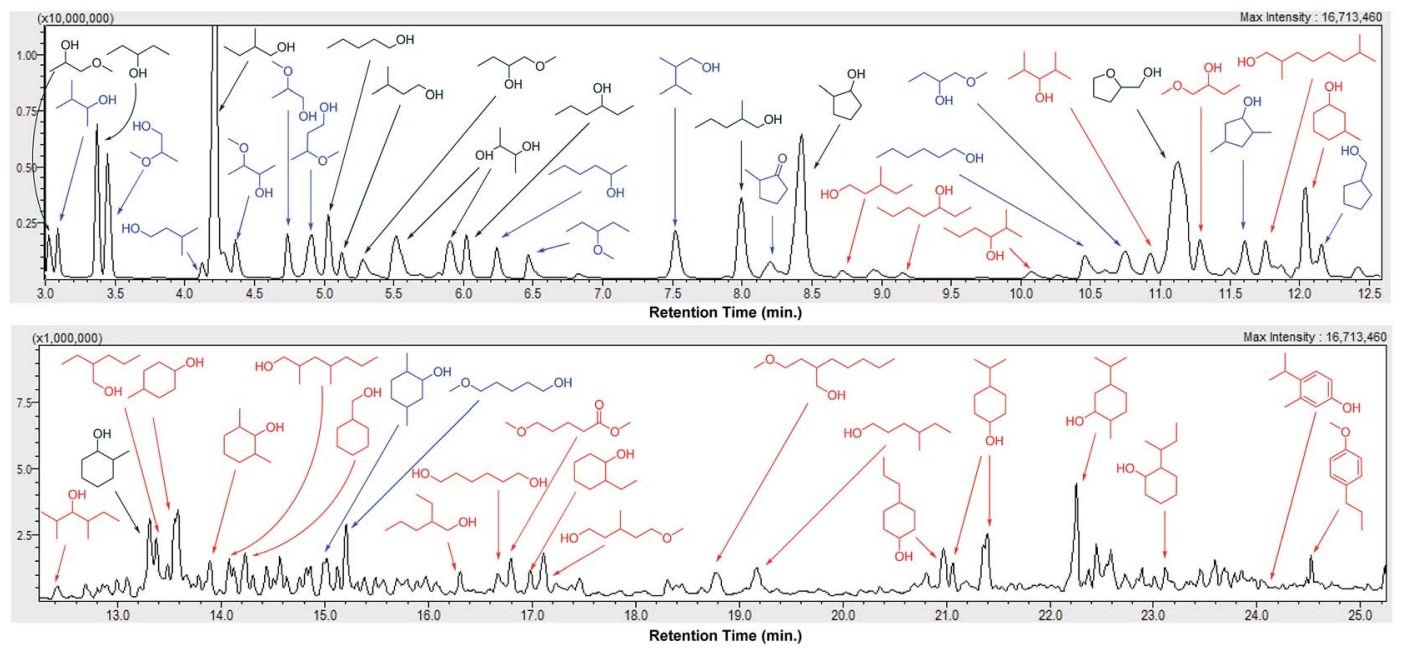

Fig. 2 GC-MS trace of a product mixture obtained upon depolymerization of pine lignocellulose using Cu20-PMO in sc-MeOH. (Product labels: green $=$ confirmed by the use of an authentic standard, blue = similarity index above $90 \%$, red $=$ similarity index between $70 \%$ and $90 \%$.) 
Organosolv lignin, separately obtained by lignocellulose fractionation, as well as pure cellulose were also reacted under the same reaction conditions with Cu20-PMO catalyst to evaluate the products obtained from these starting materials, serving as appropriate control experiments. When pure cellulose was used as starting material, the generated product mixtures had very similar distributions in the early retention time range, to those obtained from pine lignocellulose (Fig. 3) resulting in aliphatic alcohols as main products with $69.3 \%$ selectivity. Depolymerization of organosolv lignin gave good conversion of $90 \%$ and a product mixture mainly containing of substituted cyclohexanols and various phenolics (Fig. 3).

In summary, even though the mixture of products obtained with Cu5-PMO displayed slightly higher average chain length, the use of Cu20-PMO was most beneficial for achieving nearly full lignocellulose conversion ( $97 \%$ vs. $89 \%$ for Cu5-PMO). Therefore further experiments focused on the use of this catalyst composition. It has to be pointed out, that more research should focus on improving substrate/catalyst ratio for industrial application. The development of well-defined $\mathrm{Cu}$ nanoparticles or $\mathrm{Cu}$ containing bimetallic particles on appropriate supports would be desired.

\section{HDO of aliphatic alcohol model compounds}

Since the product mixtures obtained upon catalytic conversion of pine lignocellulose in sc-MeOH using Cu20-PMO consisted of mainly aliphatic alcohols, establishing a suitable HDO procedure seemed feasible. Indeed, several catalytic systems, including the use of bifunctional catalysts ${ }^{46,47}$ or the combination of a solid acid and hydrogenation catalyst ${ }^{48,49}$ have been reported for HDO of aliphatic alcohols and phenolics to alkanes. In our case, the large excess of methanol and the complexity of product mixtures and possible etherification reactions are expected to be the major challenge. Therefore, first, suitable model compound mixtures were used to discern optimal catalytic conditions and catalyst type for the desired transformation and maximize the yield of alkanes. Inspired by systems that have previously shown high efficiency for HDO of lignin derived phenolics, ${ }^{\mathbf{4 8 , 4 9}}$ we have selected to evaluate different solid acids (e.g. Nafion, HZSM-5, USY-600, $\mathrm{ZrO}_{2}$ and $\mathrm{Nb}_{2} \mathrm{O}_{5}$ ) in combination with $\mathrm{Pd} / \mathrm{C}$ as preferred hydrogenation catalyst, in a broader temperature range $\left(140-180^{\circ} \mathrm{C}\right)$.

The one pot alcohol to alkane conversion consists of the reaction sequence shown on Fig. 4, which starts with an acid catalyzed dehydration to yield the corresponding olefin, followed by a $\mathrm{C}=\mathrm{C}$ hydrogenation by $\mathrm{Pd} / \mathrm{C}$. For establishing suitable reaction conditions, cyclohexanol was identified as suitable model substrate, and its reactivity was studied in the presence of different solid acids in combination with $10 \mathrm{mg} \mathrm{Pd/}$

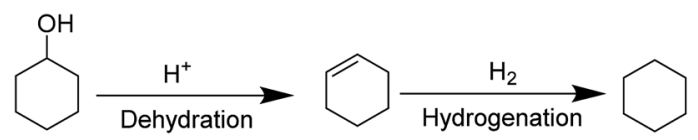

Fig. 4 Reaction sequence in the HDO of model compound cyclohexanol.
$\mathrm{C}$ under the same conditions $\left(140{ }^{\circ} \mathrm{C}, 4 \mathrm{~h}, 10 \mathrm{bar}_{2}\right)$. As can be seen in Table 1, the two zeolites (HZSM-5 and USY-600) as well as Nafion were found to be promising candidates for the conversion of cyclohexanol, giving full substrate conversion at $140{ }^{\circ} \mathrm{C}$ after 4 hours.

Moving toward real lignocellulose-derived mixtures that contain both secondary and primary alcohols of varying chain length and complexity, we first prepared model mixtures Mix1 and Mix 2 consisting of compounds relevant for the real lignocellulose depolymerization mixture. Mix1 consisted of equimolar amount of primary and secondary alcohols whereas Mix2 consisted of several primary alcohols (see Experimental section for detailed composition). Clear differences were seen in the reactivity of these mixtures (Fig. 5a vs. Fig. 5b) and especially for Mix1, the individual compounds have generally shown different reactivity pattern as well, depending on the catalyst used. While HZSM-5 was highly efficient leading to almost full conversion of all components of Mix 1 at $140{ }^{\circ} \mathrm{C}$, the other two solid acids tested showed significantly lower conversion at $140{ }^{\circ} \mathrm{C}$, especially for primary alcohols (Fig. 5a). Increasing the reaction temperature further to $160^{\circ} \mathrm{C}$ and $180^{\circ} \mathrm{C}$ lead to full conversion of all alcohols and in several cases formation of ethers was also seen. To further investigate the formation of ethers and the reactivity of primary alcohols, Mix2 containing only primary alcohols was tested (Fig. 5b). As shown in Fig. 5b, generally poor reactivity was seen at $140{ }^{\circ} \mathrm{C}$ followed by a marked increase in primary alcohol conversion at 160 and $180{ }^{\circ} \mathrm{C}$. While the substrate conversion increased dramatically for all substrate mixtures, product composition varied depending on the catalyst used in the case of Mix2. While HZSM-5 and Nafion gave almost the same results at $180^{\circ} \mathrm{C}$, and the yield of alcohols accounted for $86 \%$ and $85 \%$ respectively, with USY-600 as solid acid, substantial amount of ether by-product was found.

\section{HDO of alcohol mixtures from depolymerization of lignocellulose}

Since both HZSM- 5 and Nafion both performed well with model mixtures at $180{ }^{\circ} \mathrm{C}$, they were both selected for the following tests for the upgrading of lignocellulose derived products to alkanes. The products from depolymerization of pine lignocellulose, cellulose and pine organosolv lignin with Cu20-PMO were used as starting materials. Since the presence of

Table 1 Conversion of cyclohexanol using different solid acid catalysts with $\mathrm{Pd} / \mathrm{C}^{a}$

\begin{tabular}{lllll}
\hline & & \multicolumn{3}{c}{ Selectivity\% } \\
\cline { 3 - 5 } Entry & Solid acid & Conversion\% & Cyclohexane & Methylcyclopentane \\
\hline 1 & $\mathrm{HZSM}-5$ & 99 & 93 & 6 \\
2 & $\mathrm{USY}-600$ & 99 & 100 & 0 \\
3 & $\mathrm{ZrO}_{2}$ & 8 & 100 & 0 \\
4 & $\mathrm{Nb}_{2} \mathrm{O}_{5}$ & 0 & 0 & 0 \\
5 & $\mathrm{Nafion}$ & 99 & 99 & 1
\end{tabular}

${ }^{a}$ Reaction condition: $0.1 \mathrm{~mL}(1 \mathrm{mmol})$ cyclohexanol, $50 \mathrm{mg}$ solid acid,

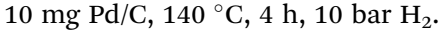



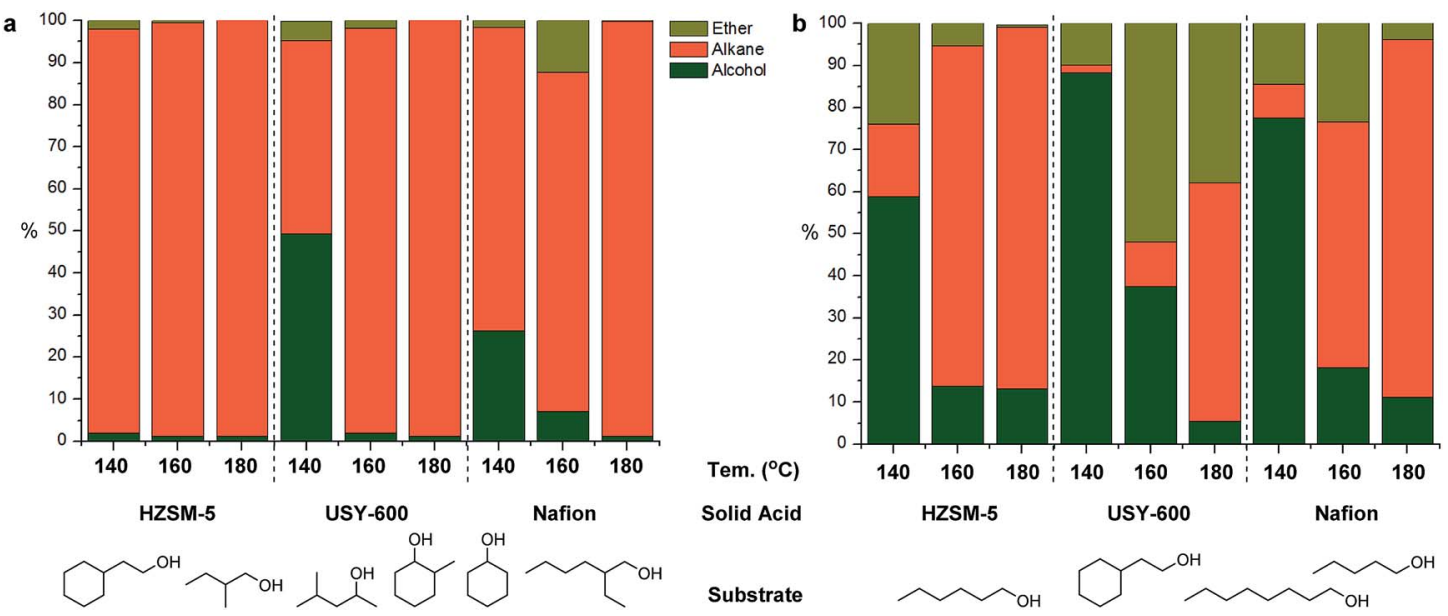

Fig. 5 Product distribution upon conversion of alcohol model compounds ((a) Mix1 and (b) Mix2) using different solid acid catalysts. Reaction conditions: $0.128 \mathrm{~mL}$ alcohol mixture 1 or $0.138 \mathrm{~mL}$ alcohol mix 2, $50 \mathrm{mg}$ solid acid catalyst, $10 \mathrm{mg} \mathrm{Pd} / \mathrm{C}, 4 \mathrm{~h}, 10$ bar $\mathrm{H}_{2}$.

methanol would hamper reactivity in further HDO reactions, we first have developed a simple solvent exchange method, that consists of adding dodecane and careful removal of methanol through rotary evaporation, whereby the vast majority of compounds remained soluble. The dodecane solution, containing most of the products, was then used for the further upgrading to alkanes. As can be seen in Fig. 6, the product mixture from pine lignocellulose was converted to alkanes in high selectivity (>83\%) with both HZSM-5 and Nafion as solid acid catalyst at $180{ }^{\circ} \mathrm{C}$ while ethers and esters remained unconverted under these reaction conditions. Slightly more of the latter two compound categories as well as other by-products $(\sim 30 \%)$ were formed when using cellulose and pine organosolv lignin derived product mixture as substrate. The by-products are mainly ethers likely formed by etherification of the produced alcohols and diols. In the case of organosolv lignin, aromatic monomers or dimers may have also decreased catalyst activity for further HDO reactions. The higher alkane yield when

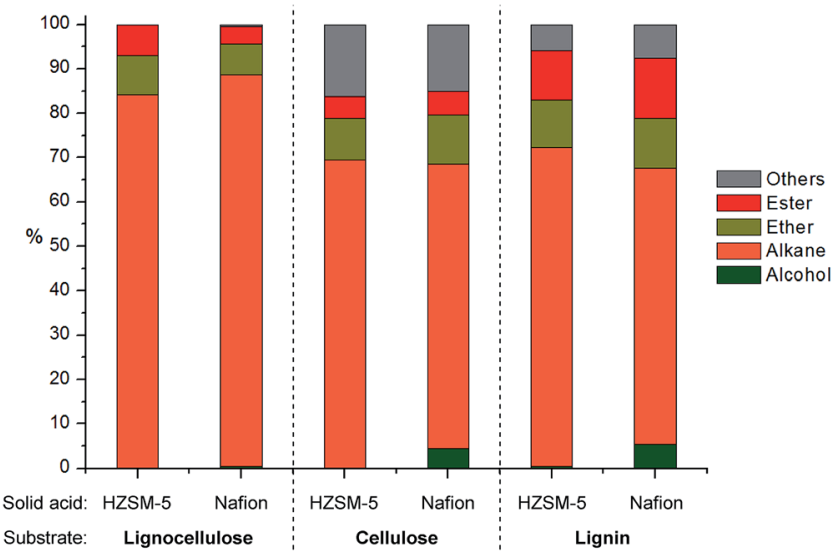

Fig. 6 Distribution of products after HDO of mixtures obtained upon pine lignocellulose, cellulose or pine organosolv lignin depolymerization. Reaction conditions: $3 \mathrm{~mL}$ products mixture in dodecane, $50 \mathrm{mg}$ solid acid catalyst, $10 \mathrm{mg} \mathrm{Pd} / \mathrm{C}, 180{ }^{\circ} \mathrm{C}, 4 \mathrm{~h}, 10$ bar $\mathrm{H}_{2}$. using lignocellulose may be also attributed to the formation of formic acid from hemicellulose, as formic acid may act as good hydrogen donor for biomass conversion, facilitating the HDO process. $^{50}$

Next, the in-depth quantitative and qualitative analysis of the alkane product mixtures was performed using GC-MS, GC-FID and GC-TCD methods. In order to calculate the yield of the obtained alkanes more accurately, the HDO method was upscaled using a crude mixtures from depolymerization of $1 \mathrm{~g}$ pine lignocellulose. As shown in Fig. 7, the obtained alkanes reflect the general structure of lignocellulose: acyclic straight or branched alkanes mainly originate from cellulose or hemicellulose while most cycloalkane components are predominantly lignin-derived. Furthermore, the chain length of the obtained alkanes range from 2 to 10, while the collected gas samples contained mainly ethane and propane. Using Nafion as solid acid catalyst resulted in higher selectivity $(30.3 \% v s$. $16.2 \%)$ of long chain alkanes (>8) as shown in Fig. 7. This could be explained with the pore size differences between Nafion $(>10$ $\mathrm{nm})$ and HZSM-5 (<1 nm). ${ }^{51}$ Furthermore, since HZSM-5 is also a good cracking catalyst, ${ }^{52}$ it may have facilitated the conversion of longer alkanes to shorter chain analogues. As shown in Table 2 , the yield of the obtained alkanes using the Pd/C + Nafion reached $25.6 \mathrm{wt} \%$, which is slightly higher than that obtained with the Pd/C + HZSM-5 catalyst system. The total carbon yield of the obtained alkanes was $48.7 \%$ and $52.9 \%$ respectively. A comparison of the alkane yield with other related research is summarized in Table S5.†

Possible reasons for loss of mass balance in this two-step process are: (a) hydrogenolysis of the lignin-methoxy groups would lead to gaseous products (e.g. methane) or methanol during Step 1; (b) loss of highly volatile organics during opening of Swagelok units as well as the solvent transfer procedure; (c) potential loss of compounds during solvent exchange (d) partial loss of highly volatile alkanes $\left(<\mathrm{C}_{4}\right)$ obtained in Step 2 before analysis. In order to address these points, more elaborate equipment that allows for careful collection of each fraction and 


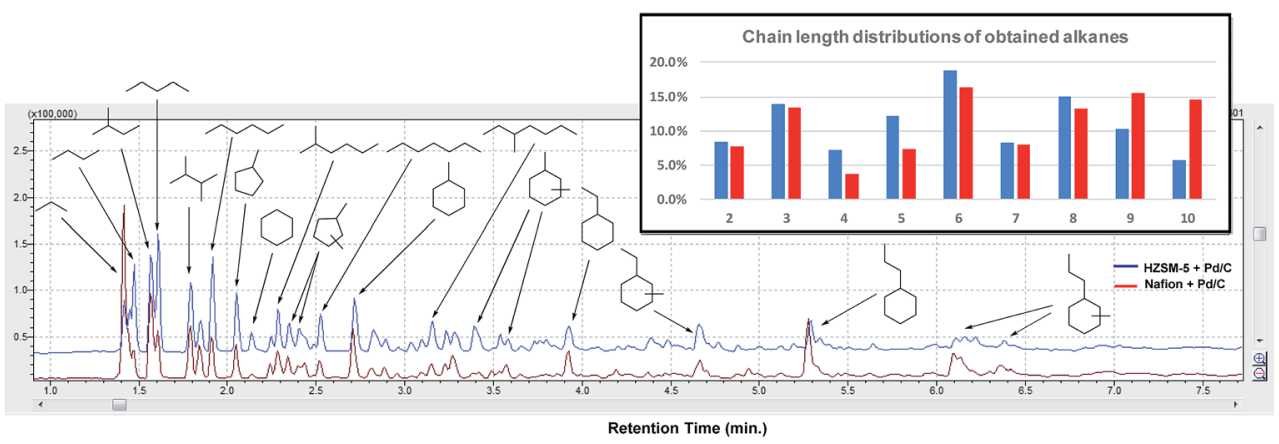

Fig. 7 GC-MS trace of the obtained alkanes after HDO of alcohols obtained by pine lignocellulose depolymerization. Distribution of chain lengths of the obtained alkane products with HZSM-5 + Pd/C versus Nafion + Pd/C.

Table 2 Quantification of the obtained alkanes after Step $1+$ Step 2 from $1 \mathrm{~g}$ pine lignocellulose

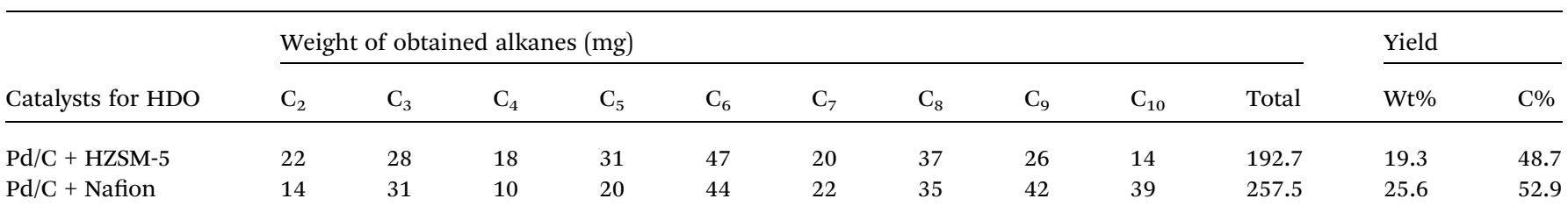

upscaling of these reactions will be required for future studies. Furthermore, testing of the combustion and fuel properties of these mixtures, which beneficially contain small amounts of methyl-ethers, as well as good amount of cyclic alkanes, should be determined in order to further asses their potential as biofuel alternatives.

\section{Conclusions}

In summary, we have established a two-step catalytic procedure for the conversion of pine lignocellulose to predominantly a mixture of alkanes that reflect the composition of the original lignocellulose substrate. The first step consists of lignocellulose deconstruction in the presence of $\mathrm{Cu}$-PMO catalysts. The second step involves the efficient HDO of these complex mixtures to linear and branched acyclic and cyclic alkanes, using Nafion and HZSM-5 in combination with $\mathrm{Pd} / \mathrm{C}$. Challenges related to the complexity of lignocellulose as well as the depolymerization mixtures have been overcome by in depth analysis, model compound and model mixture studies as well as proper quantification of the obtained alkane products. Gratifyingly, the aliphatic alcohol mixture obtained upon complete depolymerization of pine lignocellulose in Step 1 was fully converted to alkanes with an overall carbon yield around 50\% in Step 2 .

\section{Conflicts of interest}

There are no conflicts to declare.

\section{Acknowledgements}

K. B. is grateful for financial support from the European Research Council, ERC Starting Grant 2015 (CatASus) 638076.
This work is part of the research program Talent Scheme (Vidi) with project number 723.015.005 (K. B.), which is partly financed by the Netherlands Organisation for Scientific Research (NWO). Z. Sun is grateful for the financial support by the China Scholarship Council.

\section{References}

1 G. P. Robertson, S. K. Hamilton, B. L. Barham, B. E. Dale, R. C. Izaurralde, R. D. Jackson, D. A. Landis, S. M. Swinton, K. D. Thelen and J. M. Tiedje, Science, 2017, 356, eaal2324.

2 A. J. Ragauskas, C. K. Williams, B. H. Davison, G. Britovsek, J. Cairney, C. a. Eckert, W. J. Frederick, J. P. Hallett, D. J. Leak, C. L. Liotta, J. R. Mielenz, R. Murphy, R. Templer and T. Tschaplinski, Science, 2006, 311, 484-489.

3 G. W. Huber, S. Iborra and A. Corma, Chem. Rev., 2006, 106, 4044-4098.

4 D. M. Alonso, J. Q. Bond and J. A. Dumesic, Green Chem., 2010, 12, 1493-1513.

5 D. P. Robert, Biomass as Feedstock for a Bioenergy and Bioproducts Industry: The Technical Feasibility of a BillionTon Annual Supply, Oak Ridge National Laboratory, 2005.

6 S. P. S. Chundawat, G. T. Beckham, M. E. Himmel and B. E. Dale, Annu. Rev. Chem. Biomol. Eng., 2011, 2, 121-145.

7 M. Patel, X. Zhang and A. Kumar, Renewable Sustainable Energy Rev., 2016, 53, 1486-1499.

8 A. Molino, V. Larocca, S. Chianese and D. Musmarra, Energies, 2018, 11, 811.

9 T. Kan, V. Strezov and T. J. Evans, Renewable Sustainable Energy Rev., 2016, 57, 1126-1140.

10 X. Han, Y. Guo, X. Liu, Q. Xia and Y. Wang, Catal. Today, 2019, 319, 2-13. 
11 H. B. Aditiya, T. M. I. Mahlia, W. T. Chong, H. Nur and A. H. Sebayang, Renewable Sustainable Energy Rev., 2016, 66, 631-653.

12 F. Talebnia, D. Karakashev and I. Angelidaki, Bioresour. Technol., 2010, 101, 4744-4753.

13 J. Jayamuthunagai, T. Sudharsanaa, R. Praveenkumar, A. Bharghavi, B. Bharathiraja, D. Yuvaraj and M. Chakravarthy, Renewable Sustainable Energy Rev., 2016, 68, 788-807.

14 D. M. Alonso, S. G. Wettstein and J. A. Dumesic, Green Chem., 2013, 15, 584-595.

15 I. T. Horváth, H. Mehdi, V. Fábos, L. Boda and L. T. Mika, Green Chem., 2008, 10, 238-242.

16 K. Yan, Y. Yang, J. Chai and Y. Lu, Appl. Catal., B, 2015, 179, 292-304.

17 A. Mukherjee, M. J. Dumont and V. Raghavan, Biomass Bioenergy, 2015, 72, 143-183.

18 A. Démolis, N. Essayem and F. Rataboul, ACS Sustainable Chem. Eng., 2014, 2, 1338-1352.

19 B. R. Caes, R. E. Teixeira, K. G. Knapp and R. T. Raines, ACS Sustainable Chem. Eng., 2015, 3, 2591-2605.

20 Y. Román-Leshkov, C. J. Barrett, Z. Y. Liu and J. A. Dumesic, Nature, 2007, 447, 982-985.

21 S. Kang, J. Fu and G. Zhang, Renewable Sustainable Energy Rev., 2018, 94, 340-362.

22 J. Kong, M. He, J. A. Lercher and C. Zhao, Chem. Commun., 2015, 51, 17580-17583.

23 X. Wang and R. Rinaldi, Catal. Today, 2016, 269, 48-55.

24 H. Wang, H. Ruan, M. Feng, Y. Qin, H. Job, L. Luo, C. Wang, M. H. Engelhard, E. Kuhn, X. Chen, M. P. Tucker and B. Yang, ChemSusChem, 2017, 10, 1846-1856.

25 B. Op De Beeck, M. Dusselier, J. Geboers, J. Holsbeek, E. Morré, S. Oswald, L. Giebeler and B. F. Sels, Energy Environ. Sci., 2015, 8, 230-240.

26 M. Dusselier, A. Deneyer, E. Peeters, T. Ennaert, T. I. Korányi, T. Szarvas, B. F. Sels, T. Renders, N. Van Oeckel and S. Van den Bosch, Nat. Energy, 2018, 3, 969-977.

27 A. D. Sutton, F. D. Waldie, R. Wu, M. Schlaf, L. a P. Silks and J. C. Gordon, Nat. Chem., 2013, 5, 428-432.

28 S. Li, F. Chen, N. Li, W. Wang, X. Sheng, A. Wang, Y. Cong, X. Wang and T. Zhang, ChemSusChem, 2017, 10, 711-719.

29 B. L. Wegenhart, L. Yang, S. C. Kwan, R. Harris, H. I. Kenttämaa and M. M. Abu-Omar, ChemSusChem, 2014, 7, 2742-2747.

30 J. N. Chheda and J. A. Dumesic, Catal. Today, 2007, 123, 5970.
31 J. Yang, S. Li, N. Li, W. Wang, A. Wang, T. Zhang, Y. Cong, X. Wang and G. W. Huber, Ind. Eng. Chem. Res., 2015, 54, 11825-11837.

32 H. Li, A. Riisager, S. Saravanamurugan, A. Pandey, R. S. Sangwan, S. Yang and R. Luque, ACS Catal., 2018, 8, 148-187.

33 B. Fridrich, M. C. A. Stuart and K. Barta, ACS Sustainable Chem. Eng., 2018, 6, 8468-8475.

34 P. Anbarasan, Z. C. Baer, S. Sreekumar, E. Gross, J. B. Binder, H. W. Blanch, D. S. Clark and F. D. Toste, Nature, 2012, 491, 235-239.

35 Z. Sun, A. Couto Vasconcelos, G. Bottari, M. C. A. Stuart, G. Bonura, C. Cannilla, F. Frusteri and K. Barta, ACS Sustainable Chem. Eng., 2017, 5, 1738-1746.

36 Z. Sun and K. Barta, Chem. Commun., 2018, 54, 7725-7745. 37 Z. Sun, G. Bottari, A. Afanasenko, M. C. A. Stuart, P. J. Deuss, B. Fridrich and K. Barta, Nat. Catal., 2018, 1, 82-92.

38 Q. Xia, Z. Chen, Y. Shao, X. Gong, H. Wang, X. Liu, S. F. Parker, X. Han, S. Yang and Y. Wang, Nat. Commun., 2016, 7, 11162.

39 Y. Liu, L. Chen, T. Wang, Q. Zhang, C. Wang, J. Yan and L. Ma, ACS Sustainable Chem. Eng., 2015, 3, 1745-1755.

40 K. Barta and P. C. Ford, Acc. Chem. Res., 2014, 47, 1503-1512.

41 K. Barta, T. D. Matson, M. L. Fettig, S. L. Scott, A. V. Iretskii and P. C. Ford, Green Chem., 2010, 12, 1640-1647.

42 C. M. Bernt, G. Bottari, J. A. Barrett, S. L. Scott, K. Barta and P. C. Ford, Catal. Sci. Technol., 2016, 6, 2984-2994.

43 T. D. Matson, K. Barta, A. V. Iretskii and P. C. Ford, J. Am. Chem. Soc., 2011, 133, 14090-14097.

44 P. J. Linstrom and W. G. Mallard, NIST Chemistry webbook, 2001.

45 Z. Sun, G. Bottari and K. Barta, Green Chem., 2015, 17, 51725181.

46 C. Zhao and J. A. Lercher, Angew. Chem., Int. Ed., 2012, 51, 5935-5940.

47 V. Chandra Sekhar Palla, D. Shee and S. K. Maity, RSC Adv., 2014, 4, 41612-41621.

48 C. Zhao and J. a. Lercher, ChemCatChem, 2012, 4, 64-68.

49 C. Zhao, Y. Kou, A. a. Lemonidou, X. Li and J. a. Lercher, Chem. Commun., 2010, 46, 412-414.

50 R. Nie, X. Peng, H. Zhang, X. Yu, X. Lu, D. Zhou and Q. Xia, Catal. Sci. Technol., 2017, 7, 627-634.

51 D. Ohayon, R. Le Van Mao, D. Ciaravino, H. Hazel, A. Cochennec and N. Rolland, Appl. Catal., A, 2001, 217, 241-251.

52 M. A. Den Hollander, M. Wissink, M. Makkee and J. A. Moulijn, Appl. Catal., A, 2002, 223, 85-102. 